\title{
Unusual re-entry mechanisms in patients with Wolff-Parkinson-White syndrome
}

\author{
H. Neuss and M. Schlepper \\ From Kerckhoff-Klinik, Bad Nauheim, West Germany
}

\begin{abstract}
Three patients with the Wolff-Parkinson-White (WPW) syndrome were studied using His bundle recordings and programmed atrial stimulation. In two of them conduction of premature atrial depolarizations via the accessory pathway was possible when the His-Purkinje system was still refractory. The consequent conduction delay in the His-Purkinje system resulted in re-entry phenomena at the ventricular level in one case, and possibly also in another. In the third patient short runs of supraventricular tachycardia could be elicited, which were due to a longitudinal dissociation within the atrioventricular node. During these paroxysms, ventricular activation occurred over both the anomalous and the normal paths. The resulting $Q R S$ complexes resembled fusion beats as indicated by their configuration and preceding $H$ potentials.
\end{abstract}

Supraventricular tachycardias in patients with the WPW syndrome are usually thought to result from re-entry mechanisms involving both the normal and the accessory pathways of atrioventricular conduction. The increasing evidence favouring this mechanism has been largely obtained by studying these arrhythmias using intracardiac electrographic techniques (Castillo and Castellanos, I970; Narula, I973; Wellens, 197r).

Intracardiac electrograms combined with programmed atrial stimulation were used to elicit and analyse re-entry mechanisms in 3 patients with the WPW syndrome complicated by paroxysmal tachycardia. In none was the usual re-entry mechanism, involving accessory and normal pathways, responsible.

\section{Methods}

All three patients consented to the electrophysiological studies, were in a non-sedated state, and were not receiving antiarrhythmic medication at the time of the examination. A 5-polar catheter was passed via the right femoral vein and positioned to the right of the intraventricular septum adjacent to the bundle of His, according to the method of Scherlag et al. (1969). From this catheter filtered (40 to $200 \mathrm{~Hz}$ ) low atrial (A) and His bundle depolarizations $(\mathrm{H})$ were recorded. A second 4-polar catheter $(4 F)$ was positioned via the same femoral vein in the proximity of the sinus node. Two electrodes were used to record a high atrial electrogram; the two remaining electrodes served for stimulation. Simultaneously several surface electrocardiogram

Received 22 February 1974. leads were registered. The atrial stimuli consisted of rectangular impulses of $2.0 \mathrm{msec}$ duration and were twice diastolic threshold. They were applied either in the form of bigeminy or after each eighth beat during sinus rhythm or stimulated atrial rhythm. In the latter case the impulse following the premature stimulus was dropped to ensure a pause long enough for the study of re-entry mechanisms. Surface and intracardiac electrograms were recorded on magnetic tape and displayed at a paper speed of $100 \mathrm{~mm} / \mathrm{sec}$ using an ink-writing system. The following intervals were measured.

a) PA interval: from the onset of the $P$ wave in the electrocardiogram to the $\mathrm{A}$ potential in the His bundle electrogram - representing the intra-atrial part of atrioventricular conduction.

b) $P$ delta interval: from the beginning of $P$ in the electrocardiogram to the onset of the delta wave.

c) Pf interval: from the onset of the $\mathrm{P}$ wave to the junction of the QRS complex with the ST segment.

d) $A H$ interval: represents the intranodal conduction time and is measured from the onset of the A potential in the His bundle electrogram to the beginning of the His spike.

e) $\mathrm{HQ}$ interval: from the beginning of the $\mathrm{H}$ potential to the earliest appearance of the ventricular deflection in the electrocardiogram. This interval represents the shortest conduction time in the HisPurkinje system.

\section{Case I}

\section{Patients}

A 2I-year-old female patient exhibited the full picture of the WPW syndrome type B during sinus rhythm. P 
delta interval measured I30, PJ interval $290 \mathrm{msec}$. No His deflections were visible in the His bundle electrogram up to a stimulated heart rate of 185 a minute, while pre-excitation persisted without alteration in $P$ delta and PJ intervals. Then, 5:4 block of the anomalous pathway became apparent, the block increasing to $2:$ I at higher rates. Beginning at a driving frequency of 215 a minute there was a complete block of the anomalous pathway and 2:I block of the normal conduction path above the level of the bundle of His. The conducted beats showed an AH interval of $180 \mathrm{msec}$ and HQ interval of $45 \mathrm{msec}$.

After the intravenous administration of $30 \mathrm{mg}$ ajmaline there was a selective blockade of the accessory pathway. The AH interval measured $120 \mathrm{msec}$ in sinus rhythmand increased to $200 \mathrm{msec}$ at a rate of I20 a minute. Atrioventricular block above the bundle of His, with a Wenckebach phenomenon, occurred at a rate of 136 a minute. Our own findings (Neuss and Schlepper, 1973) indicate that ajmaline only causes a prolongation of the $\mathrm{AH}$ interval by about 18 per cent at this range of frequency. Hence, it is possible to obtain an approximate estimate of the conduction times of the normal atrioventricular conduction system.

In sinus rhythm the PA interval is $50 \mathrm{msec}$. If the $\mathrm{AH}$ interval is about $100 \mathrm{msec}$ and the HQ interval 45 msec, then the overall PQ time is $195 \mathrm{msec}$. The $P$ delta interval on the other hand measures $130 \mathrm{msec}$. This explains the high degree of pre-excitation. The refractory periods of the accessory pathway were studied in sinus rhythm at 60 to 70 a minute and at rates of 100 and $\mathrm{I} 20$ a minute using programmed premature atrial stimuli.

In sinus rhythm the effective refractory period of the accessory pathway was reached at a $\mathbf{P}$ stimulus interval of 380 msec (Fig. Ia). Ventricular excitation occurred exclusively over the normal pathway with an $\mathrm{AH}$ interval of 170 and an HQ interval of $65 \mathrm{msec}$. The resulting QRS was aberrant because of partial refractoriness of the His-Purkinje system, as indicated by the increase of HQ to $65 \mathrm{msec}$.

At coupling intervals between 430 and $390 \mathrm{msec}$ (Fig. Ib) each premature atrial depolarization traversed the anomalous pathway. The $\mathrm{V}$ potentials were always followed by deflections which resembled the $H$ potentials seen during normal conduction. Their distance from the preceding A was 150 to $170 \mathrm{msec}$. These potentials were not observed when the coupling interval was longer than $430 \mathrm{msec}$. At a basic cycle length of $600 \mathrm{msec}$ (100/min) the effective refractory period of the accessory pathway was reached at an $S_{1} S_{2}$ interval of $330 \mathrm{msec}$ (Fig. Ic) and ventricular excitation occurred over the normal pathway. Because of the increased basic heart rate and the more pronounced prematurity of $S_{2}, A H$ was also increased to $260 \mathrm{msec}$. Therefore, the excitation wave found the His-Purkinje system fully recovered, resulting in a normal $Q R S$ and $H Q$. At a slightly longer $S_{1} S_{2}$ interval of $340 \mathrm{msec}$, conduction over the accessory pathway was possible (Fig. Id). After $\mathrm{V}$ there was again a potential like the anterograde His potential of Fig. Ic. At coupling intervals of $350 \mathrm{msec}$ this potential was not visible (Fig. Ie).
At a basic cycle length of $500 \mathrm{msec}$ (120/min) the effective refractory period of the accessory pathway was reached at an $S_{1} S_{2}$ interval of $320 \mathrm{msec}$ (Fig. If). AH was now $270 \mathrm{msec}$ and nodal conduction resulted in a normally-shaped QRS. Total pre-excitation resulted at an $S_{1} S_{2}$ interval of $330 \mathrm{msec}$. No deflection followed the $\mathrm{V}$ potential (Fig. Ig).

The potentials following $\mathrm{V}$ as depicted in Fig. Ib and Id are most likely caused by anterograde depolarizations of the bundle of His. This explanation is favoured both by their configuration and by the fact that their distance from the preceding atrial depolarization (A) is in the same range as the $\mathrm{AH}$ interval observed during block of the accessory pathway (compare Fig. Ia with Fig. Ib, and Fig. Ic with Id). The sudden prolongation of $\mathrm{AH}$ from I90 (Fig. Id) to $260 \mathrm{msec}$ (Fig. Ic) when the coupling interval of the premature atrial depolarization was shortened by ro msec might be indicative for a dual AV nodal pathway (Denes et al., I973; Moe, Preston, and Burlington, 1956). This unique observation however will not be stressed for further discussion.

Anterograde His potentials following $\mathrm{V}$ were not"seen during regular atrial stimulation up to a rate of 185 a minute. As shown by selective blockade of the anomalous pathway after ajmaline, the delay of nodal conduction at a basic cycle length of $500 \mathrm{msec}$ ( $120 / \mathrm{min}$ ) could be expected to produce an AH time of about $200 \mathrm{msec}$. Therefore anterograde $H$ potentials are expected to appear after the $\mathrm{V}$ potentials when a basic heart rate of 120 a minute $\left(S_{1} S_{2}: 500 \mathrm{msec}\right)$ was obtained. That this was not the case is clearly seen in Fig. If and Ig in the first two beats of the basic rhythm. Though sufficient nodal conduction delay could be expected after the premature atrial depolarizations in Fig. Ie and Ig, no His deflections were registered. If the pre-excitation wave penetrates the His-Purkinje system retrogradely, then it is possible that the bundle of His is depolarized from the ventricle before inis could occur anterogradely. This suggests that the appearance of an anterograde $\mathbf{H}$ potential after $\mathrm{V}$ indicates block or delay of retrograde $\mathrm{VH}$ conduction.

In this case the effective refractory period of the accessory path is short enough to permit activation of the ventricular myocardium when the His-Purkinje system is still refractory after the previous impulse. This is shown in Fig. Ia and Ib. In Fig. ra the premature atrial depolarization was conducted solely via the atrioventricular node with an $\mathrm{AH}$ interval of 170 msec and reached the His-Purkinje system still partially refractory as indicated by the prolonged $H Q$ interval and left axis deviation. Therefore the $H$ potential of this premature atrial depolarization - related to the $\mathrm{V}$ potentials of the previous sinus beat - marks an interval in which repolarization of the His-Purkinje system was not completed. Prolongation of the coupling interval of the premature atrial depolarization by ro msec allows ventricular depolarization via the accessory path (Fig. Ib) clearly within this interval, i.e. the refractory period of the His-Purkinje system. When the basic heart rate was increased $\left(S_{1} S_{1}: 600 \mathrm{msec}\right)$ retrograde $\mathrm{VH}$ block was only evident from an $S_{1} S_{2}$ interval of $340 \mathrm{msec}$ (Fig. Id), because of the rate-dependent alterations in 

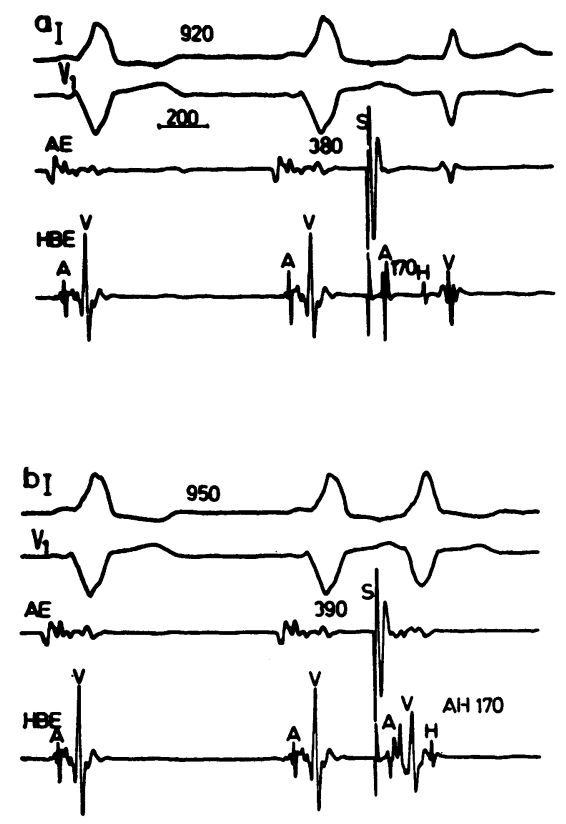
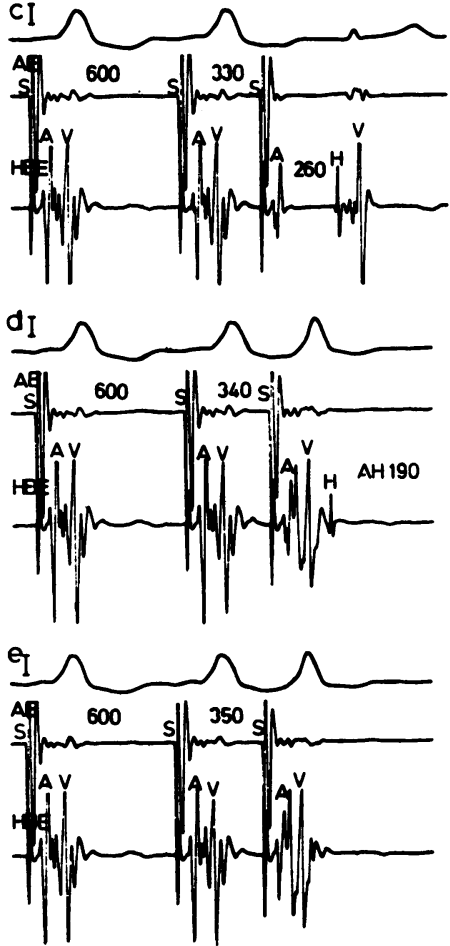

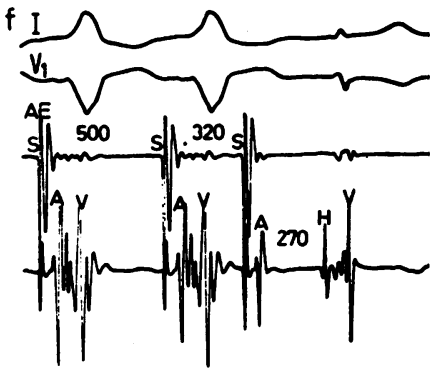

repolarization (phase 2 to 3 ) in the His-Purkinje system (Hoffman and Cranefield, r960; Trautwein and Dudel, I954). It thus appears that premature atrial depolarizations may activate the ventricular myocardium via the accessory pathway when refractory dependent conduction delay is still present in the structures of the specialized conducting system. The importance of this observation for the initiation of re-entry mechanisms at the ventricular level is emphasized by the findings in the next case.

\section{Case 2}

A 24-year-old woman with a WPW syndrome, type B, and a history of tachycardia had a $\mathbf{P}$ delta interval of
I30 and a PJ interval of 250 msec during sinus rhythm. PJ was only slightly prolonged to $270 \mathrm{msec}$ during atrial stimulation up to 180 a minute while the $P$ delta interval remained unchanged. When atrial bigeminy was induced during sinus rhythm, the effective refractory periods of both the accessory and the normal pathways were reached at a PS interval of $290 \mathrm{msec}$ (Fig. 2a). At a $P S$ interval of $300 \mathrm{msec}$ the premature atrial depolarization traversed the anomalous pathway. Following the ventricular potentials a predominant negative deflection was registered $\left(\mathrm{H}^{\prime}\right)$ at an interval of $320 \mathrm{msec}$ after the preceding stimulus. The next premature atrial depolarization, with an identical PS interval, elicited a similar deflection after $\mathrm{V}$; the $\mathrm{SH}^{\prime}$ interval was reduced to $300 \mathrm{msec}$, the preceding $\mathrm{RR}$ interval being $710 \mathrm{msec}$. 


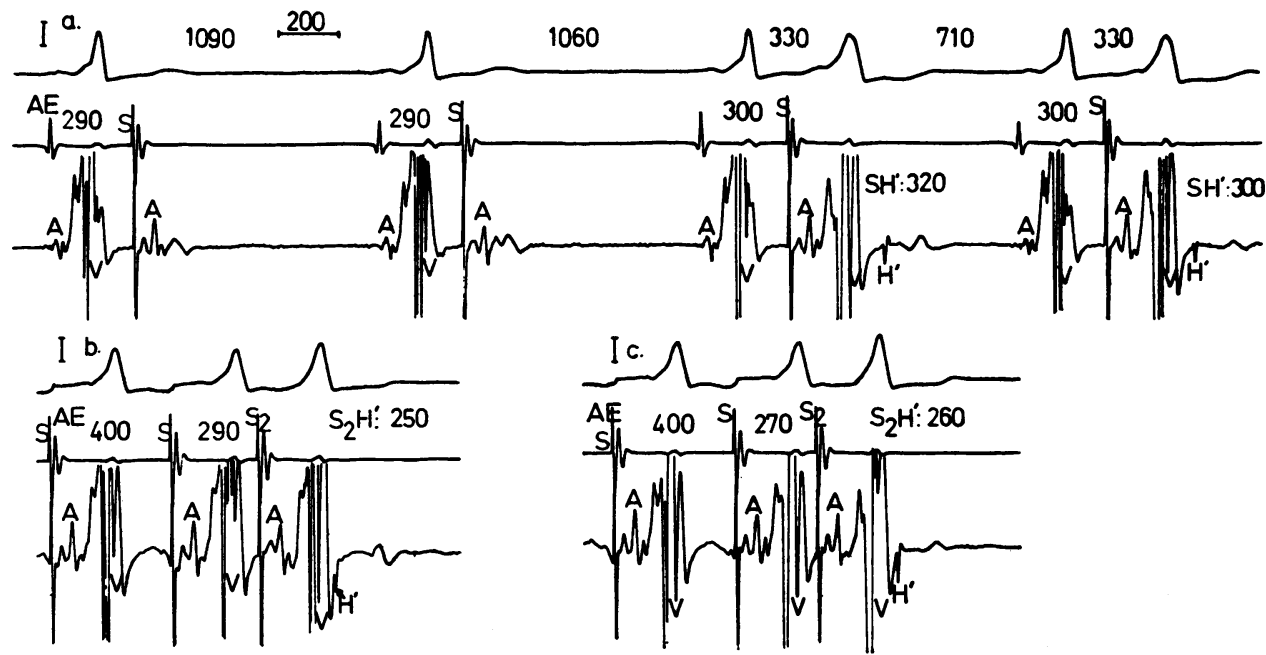

FIG. 2 (Case 2) a) Bigeminal premature atrial depolarizations (PAD) with a PS interval of 290 are ineffective. On increasing the PS interval to $300 \mathrm{msec}, P A D$ s are exclusively propagated via the accessory pathway. These $V$ potentials were followed by retrograde His depolarizations $\left.\left(H^{\prime}\right) . b\right)$ and c) At a paced rate of $150 / \mathrm{min}\left(S_{1} S_{1}=400 \mathrm{msec}\right)$ the $P A D s$ with an $S_{1} S_{2}$ interval of 290 and 270 msec, respectively, were now propagated over the accessory pathway. The $V$ potentials were followed by retrograde $H$ spikes.

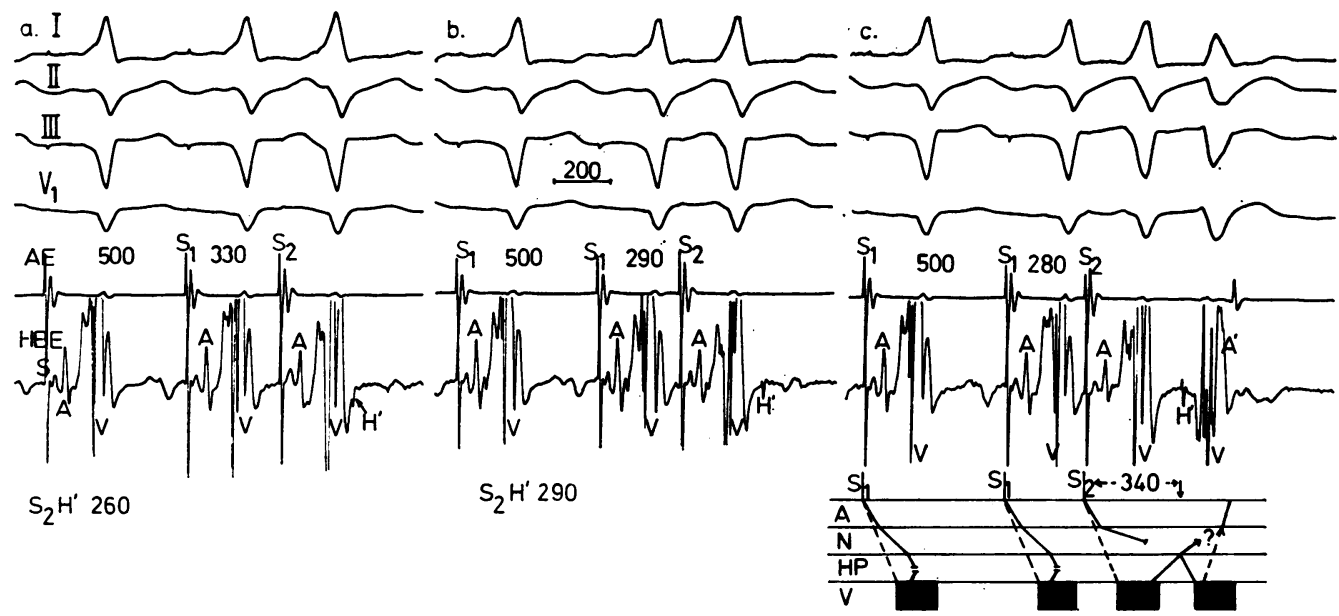

FIG. 3 (Case 2) Paced heart rate $120 / \mathrm{min}\left(S_{1} S_{1}=500 \mathrm{msec}\right.$ ). a) and b) Premature atrial depolarizations (PADs) with an $S_{1} S_{2}$ interval of 330 and $290 \mathrm{msec}$, respectively, were propagated via the accessory path; the $S_{2} H^{\prime}$ interval showed a reversed relation to the $S_{1} S_{2}$ interval. $c$ ) Shortening of the $S_{1} S_{2}$ interval to 280 msec resulted in a prolongation of $S_{2} H^{\prime}$ to 340 msec. Under this condition the $H^{\prime}$ potential was followed by a $Q R S$ of left bundle-branch block morphology and an atrial echo. The ladder diagram shows the analysis of the conduction sequences. 
This $\mathbf{H}^{\prime}$ potential became visible only at PS intervals of 300 to $350 \mathrm{msec}$ during induced atrial bigeminy.

At a paced basic heart rate of 150 a minute $\left(S_{1} S_{1}\right.$ : $400 \mathrm{msec}$ ) the effective refractory period of the accessory pathway was reduced to $220 \mathrm{msec}$, therefore, premature atrial depolarizations with an $S_{1} S_{1}$ interval of $290 \mathrm{msec}$ (Fig. 2b) and $270 \mathrm{msec}$ (Fig. 2c), respectively, were now conducted via the accessory pathway.

$H^{\prime}$ potentials were only recorded at $S_{1} S_{2}$ intervals between 290 and $260 \mathrm{msec}$. At $\mathrm{S}_{1} \mathrm{~S}_{2}$ of $290 \mathrm{msec}$ the resulting $\mathrm{S}_{2} \mathrm{H}^{\prime}$ interval was $250 \mathrm{msec}$ and became $260 \mathrm{msec}$ when $S_{1} S_{2}$ was reduced to $270 \mathrm{msec}$.

At a basic heart rate of 120 a minute $\left(S_{1} S_{1}: 500 \mathrm{msec}\right)$ $\mathrm{H}^{\prime}$ deflections were registered at $\mathrm{S}_{1} \mathrm{~S}_{2}$ intervals of 330 to 270 msec. Again the longest $\mathrm{S}_{2} \mathbf{H}^{\prime}$ interval was observed after the shortest $S_{1} S_{2}$ interval (Fig. 3). After an $S_{2} H^{\prime}$ interval of $340 \mathrm{msec}$ an early ventricular depolarization occurred, $50 \mathrm{msec}$ after the $\mathbf{H}^{\prime}$ deflection, and showed left bundle-branch block without evidence of preexcitation; $\mathrm{I} 60 \mathrm{msec}$ after $\mathrm{H}^{\prime}$ an atrial echo appeared (Fig. 3c).

Intermittent block of the accessory pathway appeared when the driving frequency was increased to 200 a minute. Atrial stimuli were sometimes exclusively propagated via the normal pathway. Preceding the QRS complexes (no. I and 8, Fig. 4) were $H$ potentials which showed a predominantly positive deflection, as opposed to the $\mathrm{H}^{\prime}$ potentials seen in Fig. 2 and 3. If the $R R$ distance was about $600 \mathrm{msec}$ (QRS 4 to 5 ) the two following excitations were propagated via the accessory pathway and succeeded regularly by a QRS complex of left bundle-branch block configuration without preexcitation (no. 7). This triplet of QRS complexes was identical to that in Fig. 3c. Hence, similar mechanisms of excitation can be assumed.

The following analysis appears to explain these find- ings. $\mathbf{H}^{\prime}$ potentials are caused by retrograde activation of the bundle of His. This assumption is favoured by 3 observations :

I) The different polarity of $\mathrm{H}$ and $\mathrm{H}^{\prime}$ potentials;

2) An increase in basic heart rate shortens the $S_{2} H^{\prime}$ interval apparently because refractory-dependent conduction delay in the His-Purkinje system diminishes with increasing heart rate (Schuilenburg and Durrer, I973; Moe and Mendez, I97I; Moe, Mendez, and Han, 1965). In the case of anterograde His activation the opposite would be expected, because of atrioventricular nodal conduction delay.

3) At higher basic heart rates $\mathbf{H}^{\prime}$ potentials occurred at shorter $S_{1} S_{2}$ intervals. This is in accordance with the well-known frequency-dependent shortening of refractory periods in the His-Purkinje system (Hoffman and Cranefield, r960; Trautwein and Dudel, r954). VH conduction delay, which results in the occurrence of retrograde $\mathbf{H}^{\prime}$ potentials should become evident at longer coupling intervals when basic heart rate is slow and at shorter $S_{1} S_{2}$ intervals when basic heart rate is faster.

In Fig. $3 \mathrm{C}$ the premature atrial depolarization leads to an early excitation of the right ventricle due to WPW syndrome type B. Propagated via the myocardium the excitation wave reaches the specialized conduction system of the left ventricle at a time when the HisPurkinje system is out of its effective refractory period. After the delayed retrograde conduction the bundle of His is depolarized and the right bundle-branch is anterogradely penetrated causing a ventricular echo of left bundle-branch block configuration. The succeeding retrograde atrial activation most probably occurs via the accessory pathway. The similarity of the configuration

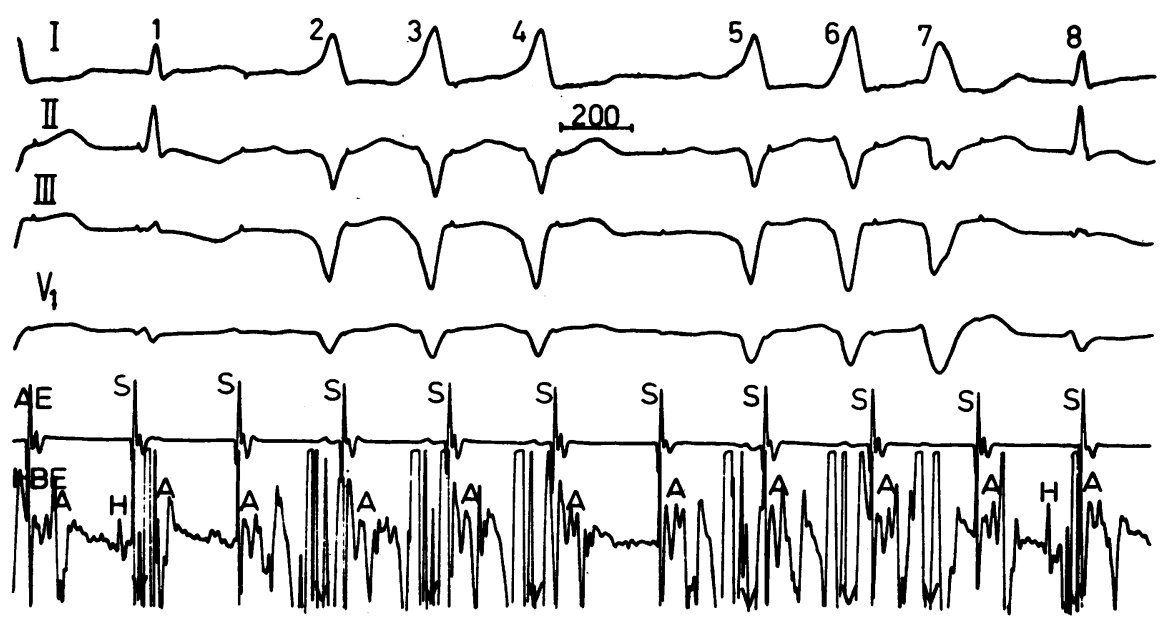

FIG. 4 (Case 2) At a regular driving rate of 200 a min (cycle length $=300$ msec) intermittent block of both the anomalous and normal pathway was evident. QRS no. 5, 6, and 7 show a triplet which resembles that in Fig. 3c, so that a similar conduction mechanism may be assumed. 
of QRS complex 7 in Fig. 4 as well as the time relation suggest that the excitation mechanisms are identical. The common features of Cases $I$ and 2 are that induced premature atrial depolarizations lead to pre-excitation of the ventricular myocardium at a time when conductivity of His-Purkinje system has not been fully restored. In Case I this is indicated by the appearance of anterograde $H$ potentials following the $V$ potentials and the occurrence of physiological interference at the level of atrioventricular node/bundle of His. In the second case the impairment of conductivity was indicated by the pronounced delay of retrograde VH conduction, especially at lower basic heart rates. This functional impairment of conductivity is the most important precondition for the development of a re-entry mechanism in the HisPurkinje system such as could be demonstrated in Case 2.

\section{Case 3}

Another re-entry mechanism was observed in a 63-yearold male patient with WPW syndrome type A. He had experienced brief paroxysms of tachycardia for at least Io years. Using atrial stimulation there was a stable conduction via the accessory pathway up to a rate of 200 a minute. At all frequency ranges the effective refractory period of the accessory pathway was found to be shorter than that of the nodal conduction path. At sinus rhythm with RR intervals between 800 and ro50 msec $H$ potentials were noted at the beginning of the delta wave in the surface electrocardiogram, AH measuring from 100 to $130 \mathrm{msec}$. Premature atrial depolarizations with a PS interval of 420 to $360 \mathrm{msec}$ were always able to elicit short runs of tachycardia.

In Fig. 5a a premature atrial depolarization with a PS interval of $420 \mathrm{msec}$ produces maximal ventricular pre-excitation, which after a delta- $A^{\prime}$ interval of 440 msec is followed by a retrograde atrial depolarization. QRS complex 4 shows less pre-excitation as shown by the $Q R S$ configuration and an $H$ spike simultaneous with the delta wave ( $A^{\prime} \mathrm{H}: 170 \mathrm{msec}$ ). $440 \mathrm{msec}$ after this ventricular echo there is another atrial echo which in
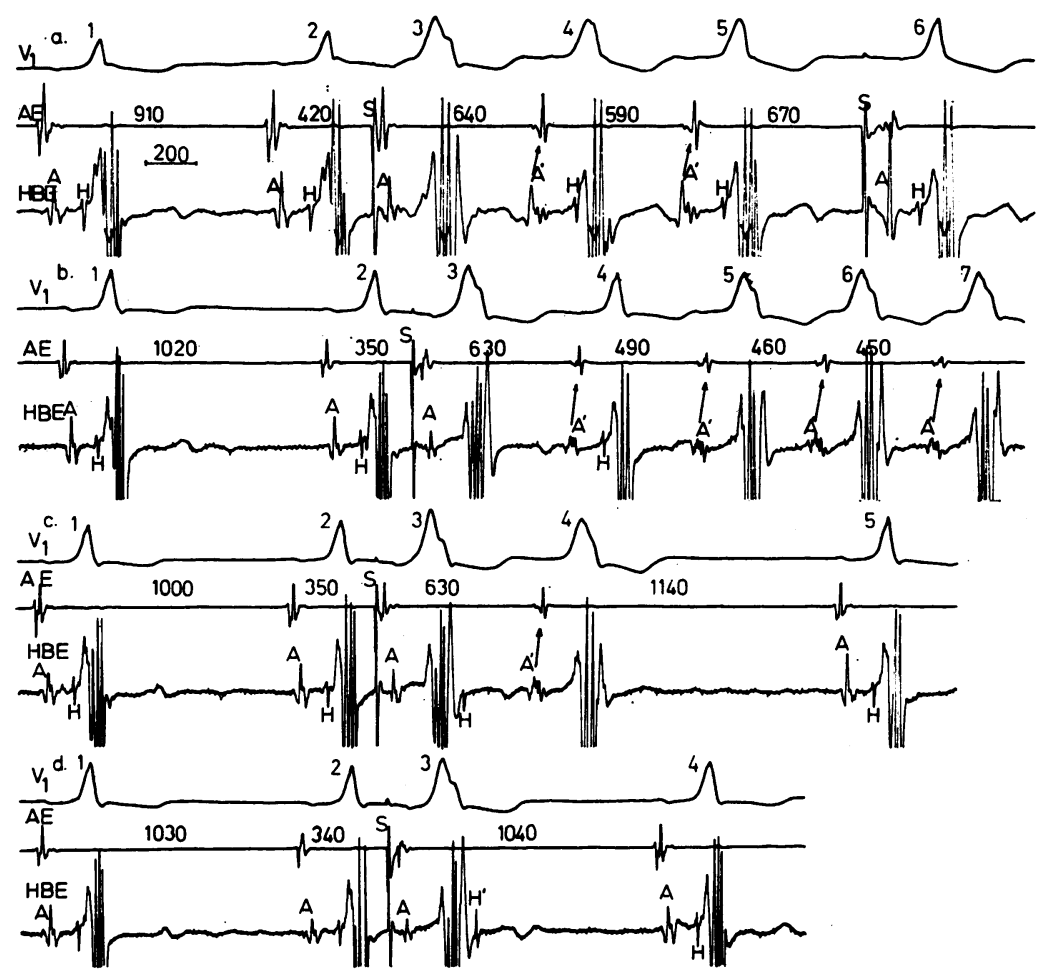

FIG. 5 (Case 3) a) A premature atrial depolarization (PAD) with a PS interval of $420 \mathrm{msec}$ produces a $Q R S$ with maximal pre-excitation, which is followed by an atrial echo. The succeeding $Q R S$ complexes no. 4 and 5 are fusion beats resulting from excitation via the normal and anomalous pathway. This is indicated by the preceding $H$ spikes. $b) A P A D$ with a coupling interval of 350 msec initiated a supraventricular tachycardia. c) A PAD with a coupling interval of $350 \mathrm{~m}$ seconly causes one atrial echo without initiating a tachycardia. d) At a further decreased coupling interval ( $340 \mathrm{msec}$ ) anterograde nodal conduction was delayed so that the bundle of His could be depolarized retrogradely. 
turn leads to another ventricular activation. This QRS (no. 5) also showed evidence of propagation via both the normal and anomalous pathway. QRS 5 and 4 are therefore fusion beats as are QRS I and 2. The more pronounced degree of pre-excitation is caused by the ratedependent prolongation of $\mathrm{AH}$ interval from 120 to 170 msec. There is no retrograde atrial activation following QRS 5, so the re-entry mechanism is terminated. The next stimulated excitation is not relevant to the explanation of the underlying mechanism. A premature atrial depolarization with a PS interval of 350 msec (Fig. 5b) was followed by a fully pre-excited QRS (no. 3), which was in turn succeeded by retrograde activation of the atria. This in consequence produces a fusion beat with an AH interval of 150 msec initiating a spell of tachycardia. Because of the shorter RR intervals (490 to $450 \mathrm{msec}$ ) and the rate-dependent prolongation of $\mathrm{AH}$, the next QRS complexes show maximal pre-excitation, but are always preceded by retrograde atrial activation. Apparently at this PS interval borderline conditions are reached. In Fig. $5 \mathrm{c}$ the same PS interval only leads to an atrial echo but does not initiate a tachycardia. Contrary to Fig. 5b the anterograde $\mathrm{H}$ spike (AH: $280 \mathrm{msec}$ ) succeeds the fully pre-excited stimulated QRS. The fact that the observed atrial echo was followed by a ventricular depolarization with pronounced pre-excitation (QRS complex no. 4), while no His potential was discernible, favours the interpretation that anterograde block supra His has occurred and prevented repetitive reciprocation. By reducing PS to $340 \mathrm{msec}$ (Fig. 5d), the stimulated QRS complex is succeeded by a predominant positive deflection (AH': $280 \mathrm{msec}$ ) which probably presents a retrograde His spike (due to block or greater delay in anterograde atrioventricular nodal conduction). An atrial echo could not be elicited.

The brief paroxysms are most probably initiated and maintained by a re-entry mechanism sparing the accessory pathway. Premature atrial depolarizations with a PS interval of 420 to $350 \mathrm{msec}$ (echo range) meet the atrioventricular node in the state of longitudinal dissociation. The excitation reaches the bundle of His via fibres with a short refractory period (alpha-path) while anterograde conduction was blocked in other fibres with a longer refractory period (beta-path). If the distal atrioventricular node was reached with a critical delay, reciprocation via the now recovered beta-path is possible and leads to an atrial echo (Mendez and Moe, 1966; Denes et al., 1973; Schuilenburg and Durrer, I968; Goldreyer and Damato, 197I). This is again propagated over the alpha-pathway and the accessory pathway (bundle of Kent), eliciting ventricular fusion beats.

\section{Discussion}

A predisposing mechanism for the initiation of reciprocating tachycardias is the presence of two parallel conducting atrioventricular pathways with different functional properties (Schamroth and Yoshonis, 1969). In patients with WPW syndrome reciprocating tachycardia are thought to involve two separate anatomical communications (Durrer et al.,
1967), one of them the accessory path and the other the normal atrioventricular pathway. Premature atrial depolarizations with a critical coupling interval may find one path refractory (path $A$ ) while atrioventricular conduction via the other path (path B) is possible (Durrer et al., 1967; Castillo and Castellanos, 1970; Narula, 1973). On the ventricular level the impulse may enter path $A$ and return to the atria. If the initial pathway is responsive once again circus movement may continue. If the accessory pathway is traversed retrogradely and the normal path is used for anterograde conduction pre-excitation will disappear. If, however, the anomalous path is used for atrioventricular conduction QRS complexes will show maximal pre-excitation during supraventricular tachycardia.

Generally re-entry tachycardias involving parallel conducting structures may occur in any part of the conducting system (Mendez and Moe, r966; Wellens, Schuilenburg, and Durrer, 1972). Their analysis is impossible to achieve by use of the surface electrocardiogram. Special techniques with intracardiac registration of electrograms and programmed atrial and ventricular stimulation are necessary to differentiate between intranodal reentry, re-entry in the His-Purkinje system, and reentry involving the atrioventricular node/His system and an accessory atrioventricular connexion.

According to our analysis, Case 2 demonstrates a re-entry mechanism at the ventricular level which is thought to be the underlying mechanism in certain forms of ventricular tachycardia. Circus movement in these tachycardias, which can include the bundle-branches as well as the bundle of His, have been studied with programmed stimulation (Wellens et al., 1972). However, documentation of the conduction sequence within His-Purkinje system is still lacking. In animal experiments this mechanism was well established by the studies of Moe et al. (1965).

Although in the first patient no re-entry phenomenon could be provoked, the findings support the conclusions drawn in Case 2. It could be demonstrated that in both patients the functional properties of the accessory pathway were quite different from those of the His-Purkinje system. This permits the propagation of premature atrial depolarizations to the ventricle at a time when a repolarization of the His-Purkinje system had not been fully completed. Phase 3 dependent conductivity impairment is the premise for re-entry mechanisms in the His-Purkinje system. It seems possible that atrial premature beats may not only cause single echo phenomena as in the second patient but may initiate self-maintaining ventricular tachycardia in the WPW syndrome. 
The existence of longitudinal dissociation in the normal atrioventricular conduction pathway and the presence of an accessory pathway of the Kent bundle type is the explanation for the re-entry mechanism observed in the third patient. A similar assumption has been made by Wellens (197I), to interpret the initiation of a supraventricular tachycardia by double ventricular stimuli in a patient with WPW syndrome. However, the explanation is limited to the initiation of the tachycardia. Findings suggesting a coexistence of accessory atrioventricular pathways, and dual atrioventricular nodal pathways are described by Spurrell, Krikler, and Sowton (1973) and by Friedberg and Schamroth (1973). In our patients the findings clearly indicate that the accessory pathway takes part neither in the initiation nor in the maintenance of the tachycardia and that conduction over the accessory pathway was incidental.

\section{References}

Castillo, C. A. and Castellanos, A. (1970). His bundle recordings in patients with reciprocating tachycardias and Wolff-Parkinson-White syndrome. Circulation, 42, 271.

Denes, P, Wu. D., Dhingra, R. C., Chuquimia, R., and Rosen, K. M. (1973). Demonstration of dual A-V nodal pathways in patients with paroxysmal supraventricular tachycardia. Circulation, 48, 549.

Durrer, D., Schoo, L., Schuilenburg, R. M., and Wellens, H. J. J. (1967). The role of premature beats in the initiation and the termination of supraventricular tachycardia in the Wolff-Parkinson-White syndrome. Circulation, 36, 644 .

Friedberg, H. D., and Schamroth, L. (1973). Three atrioventricular pathways: reciprocating tachycardia with alternation of conduction times. Fournal of Electrocardiology, 6, 159 .

Goldreyer, B. N., and Damato, A. N. (197I). The essential role of atrioventricular conduction delay in the initiation of paroxysmal supraventricular tachycardia. Circulation, $43,679$.

Hoffman, B. F., and Cranefield, P. F. (1960). Electrophysiology of the Heart. McGraw-Hill, New York.
Mendez, C., and Moe, G. K. (1966). Demonstration of a dual A-V nodal conduction system in the isolated rabbit heart. Circulation Research, 19, 378.

Moe, G. K., and Mendez, C. (1971). Functional block in the intraventricular conduction system. Circulation, 43, 949.

Moe, G. K., Mendez, C., and Han, J. (1965). Aberrant A-V impulse propagation in the dog heart: a study of functional bundle branch block. Circulation Research, 16, 261.

Moe, G. K., Preston, J. B., and Burlington, H. (1956). Physiologic evidence for a dual A-V transmission system. Circulation Research, 4, 357.

Narula, O. S. (1973). Wolff-Parkinson-White syndrome. A review. Circulation, 47, 872.

Neuss, H., and Schlepper, M. (1973). Die Aussagefähigkeit verschiedener Stimulationsverfahren bei Untersuchungen über die A-V Utberleitung - dargestellt an der Einwirkung von Ajmalin. Verhandlungen der Deutschen Gesellshaft für Kreislaufforschung, 39, 222.

Schamroth, L., and Yoshonis, K. F. (1969). Mechanisms in reciprocal rhythm. American fournal of Cardiology, 24, 224.

Scherlag, B. J., Lau, S. H., Helfant, R. H., Berkowitz, W. D., Stein, E., and Damato, A. N. (1969). Catheter technique for recording His bundle activity in man. Circulation, 39, I3.

Schuilenburg, R. M., and Durrer, D. (1968). Atrial echo beats in the human heart elicited by induced atrial premature beats. Circulation, 37, 680 .

Schuilenberg, R. M., and Durrer, D. (1973). Rate-dependency of functional block in the human His bundle and bundle branch-Purkinje system. Circulation, 48, 526 .

Spurrell, R. A. J., Krikler, D., and Sowton, E. (I973). Two or more intra AV nodal pathways in association with either a James or Kent extranodal bypass in 3 patients with paroxysmal supraventricular tachycardia. British Heart fournal, 35, II3.

Trautwein, W., and Dudel, J. (1954). Aktionspotential und Mechanogramm des Warmblüterherzmuskels als Funktion der Schlagfre quenz.Archiv für die Gesamte Physiologie des Menschen und der Tiere, 260, 24.

Wellens, H. J. (197I). Electrical Stimulation of the Heart in the Study and Treatment of Tachycardias. Kroese, Leiden, Netherlands.

Wellens, H. J., Schuilenburg, R. M., and Durrer, D. (1972). Electrical stimulation of the heart in patients with ventricular tachycardia. Circulation, 46, 216.

Requests for reprints to Dr. M. Schlepper, KerkhoffKlinik, 635 Bad Nauheium, Benekestr. 6-8, West Germany. 